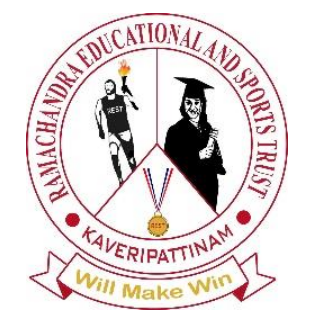

REST Journal on Emerging trends in Modelling and Manufacturing

Vol: 6(1), 2020

REST Publisher

ISSN: 2455-4537

Website: www.restpublisher.com/journals/jemm

\title{
Separation methods for produced water treatment: A study in the oil fields of
}

\author{
Assam \\ Riku Dutta \\ Assam Energy Institute, Sivasagar, a centre of Rajiv Gandhi Institute of Petroleum Technology \\ rikudutta14@gmail.com
}

\begin{abstract}
Produced water management is one of the major challenges in the present oil \& gas exploration industry. Produced water includes the water which accompanies the oil and gas during the production phase of a well as well as the water injected for stimulation of fractures. Millions of barrels of water are produced each year as new wells are drilled in different parts of the world. Oil field produced water contains substantial quantity of oil and Grease and other suspended particles and therefore, it cannot be disposed off directly or cannot be injected to the sub surface for secondary recovery purposes considering stringent disposal norms set by environmental regulation policies. Moreover among 3\% of all water on earth, only $0.29 \%$ of World's freshwater are easily accessible (USGS, 2005). If this waste water from oil wells can be recycled and reused, it can effectively reduce the produced water disposal volumes by approximately $85 \%$ to $100 \%$. Although, studies were conducted pertaining to its beneficial reuse and potential environmental risk assessment in connection to toxicity and known contaminant concentration. This study focuses on the study of the available water treatment methods applied in the various oil fields of Assam to meet the regulatory norms for disposal and re-injection of produced water as Assam being most potential oil and gas producer in India. The study also highlights some of the advanced technologies that can be used to treat the produced water considering not only the safe disposal norms but also as a source of fresh water.
\end{abstract}

Keywords: Produced water, Effluent treatment plant, water injection plant, Primary/secondary/tertiary treatment methods, fresh water, membrane technology, electro-chemistry, Macro porous polymer exchange technology.

\section{Introduction}

Drilling waste management is one of the critical element in the successful completion of a drilling process. During drilling operation, water is produced as the main drilling waste. The large volume of produced water needs to be disposed of safely following various regulatory norms and if it is to be used for secondary recovery purposes then it has to be treated to lower its hydro-carbon content and Total suspended solid (TSS) particles to acceptable limits. The cost of separation, treatment and disposal, and the environ-mental impacts of discharging are the main, substantial issues. Water production now dominates many oilfield operations since most of the reserves have reached their peak and are in declining stage. The oil and gas industry produces approximately 14 billion bbls of water annually and the annual expenditure on processing of this water was estimated to around 40-45 billion dollars worldwide [1,2]. The American Petroleum Institute (API) estimated that $71 \%$ of produced water is being used for Improved Oil Recovery (IOR), 21\% is being injected for disposal, 5\% to beneficial use such as livestock, irrigation, etc. and 3\% to percolation and evaporation ponds. Membrane filtration is a technology that has been successfully practiced for many decades and demonstrates obvious technical and economical feasibilities. Overall, the membrane field has advanced immensely. Membranes are economical, environmentally friendly, versatile and easy to use, making them a leading choice for water purification applications which should continue to be the case for many years to come.

\section{What is Produced Water?}

In subsurface formations, naturally occurring rocks are generally permeated with fluids such as water, oil, or gas (or some combination of these fluids). It is believed that the rock in most oil-bearing formations is completely saturated with water prior to the invasion and trapping of petroleum [3]. The less dense hydrocarbons migrated to trap locations, displacing some of the water from the formation in becoming hydro-carbon reservoirs. Thus, reservoir rocks normally contain both petroleum hydrocarbons (liquid and gas) and water. This water is frequently referred to as "connate water" or "formation water" and becomes produced water when the reservoir is produced and these fluids are brought to the surface. Produced water is any water that is present in a reservoir with the hydrocarbon resource and is produced to the surface with the crude oil or natural gas. 


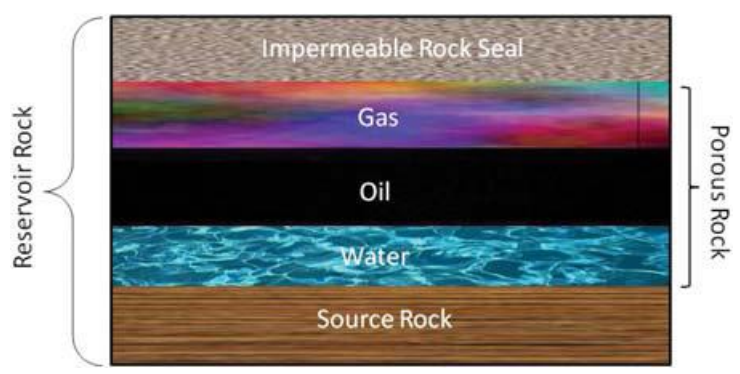

Fig: 1 A typical reservoir

3. Produced Water Characteristics

Table 1: APCB specification for disposal

\begin{tabular}{|c|c|c|}
\hline \multicolumn{3}{|c|}{ Produced water quality of Assam } \\
\hline Parameter & Unit & Values \\
\hline PH & - & $7.38-7.8$ \\
\hline TSS & ppm & $250-1300$ \\
\hline TDS & ppm & $3500-5000$ \\
\hline Turbidity & NTU & $130-1130$ \\
\hline Oil \& Grease & ppm & $200-1300$ \\
\hline
\end{tabular}

Produced water is not a single commodity. The physical and chemical properties of produced water vary considerably depending on the geographic location of the field, the geological formation with which the produced water has been in contact for thousands of years, and the type of hydrocarbon product being produced. Oil and grease are the constituents of produced water that receive the most attention in both onshore and offshore operations, while salt content (expressed as salinity, conductivity, or TDS) is a primary constituent of concern in onshore operations. In addition, produced water contains many organic and inorganic compounds. The organic and inorganic components of produced water discharged from wells can be in a variety of physical states including solution, suspension, emulsion, adsorbed particles, and particulates [4]. The various constituents of produced water are 1. Dispersed oil, 2. Dissolved or Soluble Organic Components, 3. Treatment Chemicals, 4. Produced Solids, 5. Scales, 6. Bacteria, 7. Metals, 8. Sulfates, 9. Naturally Occurring Radioactive Material (NORM).

\section{Produced water quality and disposal norms of Assam} Table 2: Produced water quality of Assam

\begin{tabular}{|c|c|c|}
\hline \multicolumn{2}{|c|}{ APCB specification for sub-surface disposal below 1000 m } \\
\hline Parameters & Unit & Range \\
\hline Oil \& Grease & $\mathrm{ppm}$ & 10 (Max.) \\
\hline $\mathrm{pH}$ & - & $6.0-8.5$ \\
\hline TDS & $\mathrm{ppm}$ & 2100 (Max.) \\
\hline TSS & $\mathrm{ppm}$ & 100 (Max.) \\
\hline COD & $\mathrm{ppm}$ & 100 (Max.) \\
\hline BOD & $\mathrm{ppm}$ & 30 (Max.) \\
\hline Salinity & $\mathrm{ppm}$ & 600 (Max.) \\
\hline
\end{tabular}

Table 3: Parameters in treated water from an ETP

\begin{tabular}{|c|c|c|c|}
\hline \multicolumn{5}{|c|}{ Parameters maintained in drinking water } \\
\hline Sl. No. & Parameter & Unit & Values \\
\hline $\mathbf{1}$ & $\mathrm{P}^{\mathrm{H}}$ & - & $6.85-8.5$ \\
\hline $\mathbf{2}$ & TSS & ppm & $<1$ \\
\hline $\mathbf{3}$ & TDS & ppm & 500 \\
\hline $\mathbf{4}$ & Turbidity & NTU & 1 \\
\hline $\mathbf{5}$ & Oil \& Grease & ppm & $<2$ \\
\hline
\end{tabular}

Table 4: Characteristics of Drinking water

\section{Parameters maintained in treated water}

Sl. No.
Unit

Values 


\begin{tabular}{|c|c|c|c|}
\hline & & & \\
\hline $\mathbf{1}$ & $\mathrm{P}^{\mathrm{H}}$ & - & $7.65--7.85$ \\
\hline $\mathbf{2}$ & $\mathrm{TSS}$ & $\mathrm{ppm}$ & $20--30$ \\
\hline $\mathbf{3}$ & TDS & $\mathrm{ppm}$ & $1000-1200$ \\
\hline $\mathbf{4}$ & Turbidity & NTU & $18--25$ \\
\hline $\mathbf{5}$ & Oil \& Grease & $\mathrm{ppm}$ & $9-10$ \\
\hline
\end{tabular}

Oil production from the oil fields of Assam is accompanied by a high amount of water production (around 70\%).The liquid produced from the wells flow to the nearby Group Gathering Station (GGS)/Oil Collecting station(OCS) where it is separated into three phases viz. Oil, water and gas. The oil separated goes to the Central Tank Farm (CTF) area for dispatch/sale to the refinery. The water commonly known as Effluent which is separated in the GGS/OCS contains substantial quantity of oil and grease and other suspended particles. Therefore, it cannot be disposed off directly or cannot be injected to the sub surface for secondary recovery purposes keeping in view environmental concerns.

The water therefore has to be treated to maintain the values of $\mathrm{pH}$, Turbidity, Total dissolved solids (TDS), Total suspended solids (TSS) and Oil \& Grease in the range specified by Assam Pollution Control Board (APCB) for disposal purpose and industry specific norms for water injection purpose. Moreover if this water has to be used for other purposes like irrigation, agriculture, potable water etc. the various standards has to be maintained. Thus, Effluent Treatment plant (ETP) and the Water Injection Plant (WIP) are installed at various production installations to meet the treated water quality parameters. Effluent treatment can involve physical, chemical or biological processes or combinations of these processes depending on the quality of produced effluent water and required outflow standards. Effluent treatment is usually characterized as consisting of three sequential separation processes - Primary, Secondary and Tertiary treatment.

\section{A. Primary treatment method \\ 1. API Separator}

The API separator is a gravity separation device designed by using Stokes Law. The design of the separator is based on the specific gravity difference between the oil and the wastewater because that difference is much smaller than the specific gravity difference between the suspended solids and water. Based on that design criterion, most of the suspended solids will settle to the bottom of the separator as a sediment layer, the oil will rise to top of the separator, and the waste water will be the middle layer between the oil on top and the solids on the bottom. Typically, the oil layer is skimmed off and subsequently re-processed or disposed of, and the bottom sediment layer is removed by a chain and flight scraper (or similar device) and a sludge pump. The water layer is sent to further treatment $[5,6]$.

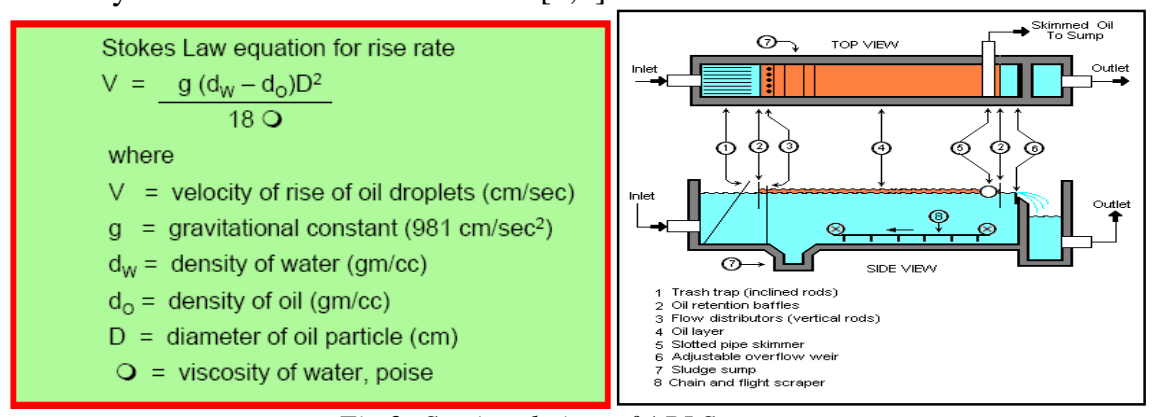

Fig 2: Sectional view of API Separator

\section{Flotation Units}

Flotation units are the only commonly used water treating equipment that does not rely solely on gravity separation of the oil droplets. In these units, fine gas bubbles are generated and dispersed in water, where they coalesce themselves to oil droplets or solid particulates thus reducing the overall density of oil droplets. The gas bubbles then help to lift the oil to the water surface for collection. Flotation aids such as coagulants, poly electrolytes, or demulsifies are added to improve performance. There are currently three conventional flotation techniques: electro-flotation (EF), Induced (dispersed) air flotation (IAF) and dissolved air flotation (DAF) [7] that are distinguished by the method employed in producing the small gas bubbles needed to contact the water. IAF and DAF have been used extensively in the removal of stable oil emulsions [8]. IAF utilizes bubbles between 40 to $1000 \mu \mathrm{m}$ in size, turbulent hydrodynamic conditions, where the process has low retention times; normally < 5 minutes. DAF on the other hand employs micro bubbles 30-100 $\mu \mathrm{m}$ in size and quiescent regimes; however, because retention times are higher (20 to 60 minutes), it is inefficient when treating high volume effluents and high flow rates [7]. The presence of emulsified oil in water, droplets around $50 \mu \mathrm{m}$ in size causes problems in phase separation by conventional techniques. The flotation separation of very fine oil droplets $(2$ to $30 \mu \mathrm{m})$ is even more complicated and usually requires fine bubbles, quiescent hydrodynamic conditions in the cell separation zone or emulsion breakers prior to flotation [9]. This therefore suggests that the micro bubbles and the quiescent regimes employed by make it the best technique for separation of very fine 
oil droplets. Pre-treatment of the emulsified oil in water using coagulation/flocculation or adsorption are methods that can be used to effect emulsion breaking prior to flotation in order to optimize the performance of DAF.

\section{Flocculator}

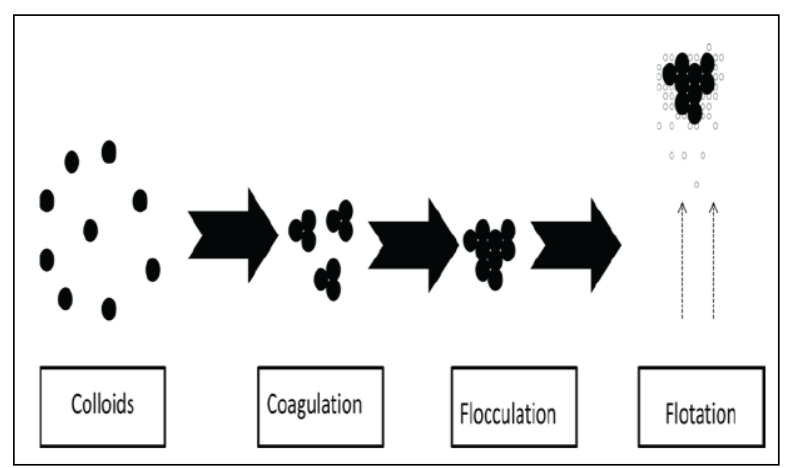

Fig: 3 Process of Coagulation, Flocculation and Flotation

Colloidal and emulsified particles are too small to be removed by floatation or sedimentation and most filtration systems. To remove them by these systems they have to be forced to form bigger, floc-like particles. This is achieved by a process called coagulation-flocculation by adding chemicals to the water in a flocculator. The coa-gulation process involves adding iron or aluminum salts, such as Aluminum or copper sulphate, ferric sulphate, ferric chloride or polymers, to the water. These chemicals are called coagulants, and have a positive charge. During the reaction, the positive charge of the coagulant neutralizes the negative charge of dissolved and suspended particles in the water and these particles bind together or coagulates (this process is sometimes also called flocculation) to produce flocs. The larger particles, or floc, are heavy and quickly settle to the bottom of the water supply. This settling process is called sedimentation.

\section{B. Secondary Treatment methods}

\section{Trickling Filter}

A trickling filter consists of a fixed bed of rocks, lava, coke, gravel, slag, polyurethane foam, sphagnum peat moss, ceramic, or plastic media over which sewage or other wastewater flows downward and causes a layer of microbial slime (biofilm) to grow, covering the bed of media. Aerobic conditions are maintained by splashing, diffusion, and either by forced air flowing through the bed or natural convection of air if the filter medium is porous. The removal of pollutants from the wastewater stream involves both absorption and adsorption of organic compounds by the layer of microbial biofilm. As the biofilm layer thickens, it eventually sloughs off into the treated effluent and subsequently forms part of the secondary sludge. Typically, a trickling filter is followed by a clarifier or sedimentation tank for the separation and removal of the sloughing.

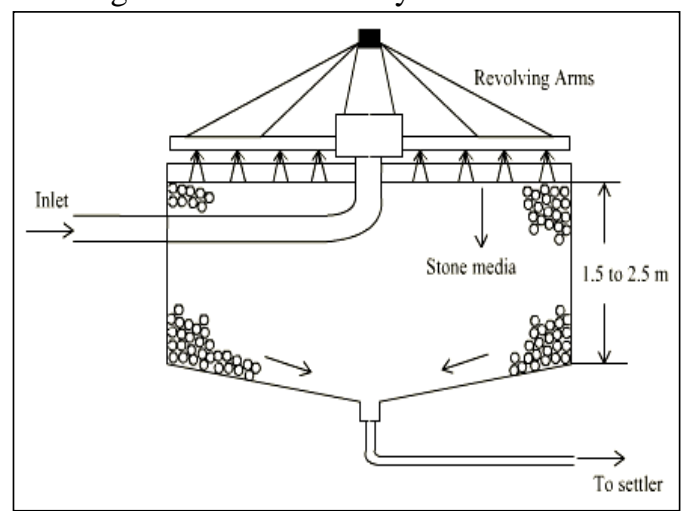

Fig:4 Trickling filter

\section{Clarifier}




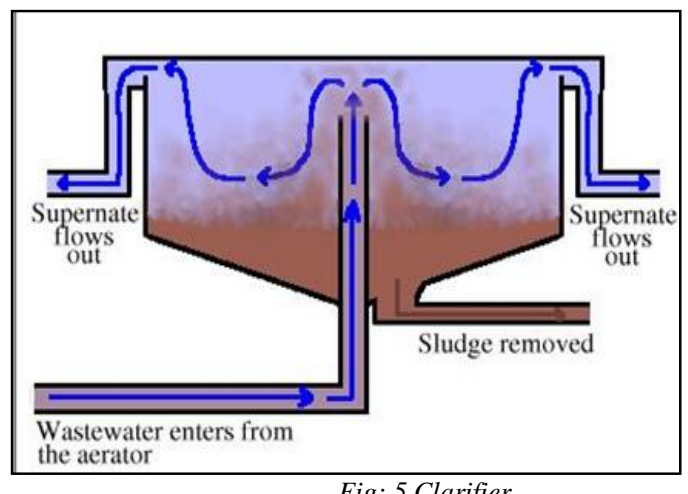

The objective of clarifier is to settle and remove all the suspended matter (Sludge particle/micro-organism growth) and the floating scum. It is a conical bottom tank provided with a revolving scraper or collector arm. It is a continuous sedimentation. The clean influent flows down the circular weir into the outer launder (or cleaning agent) running down the side of the tank. The sludge goes to the sludge driver via the sludge lagoon. A portion of the biological sludge is recycled back to the bioreactor. Cowdung is also added during start up. Sometimes septic tank sludge is also added as a source of micro-organism.

\section{Tertiary Treatment method}

\section{Pressure Sand Filter}

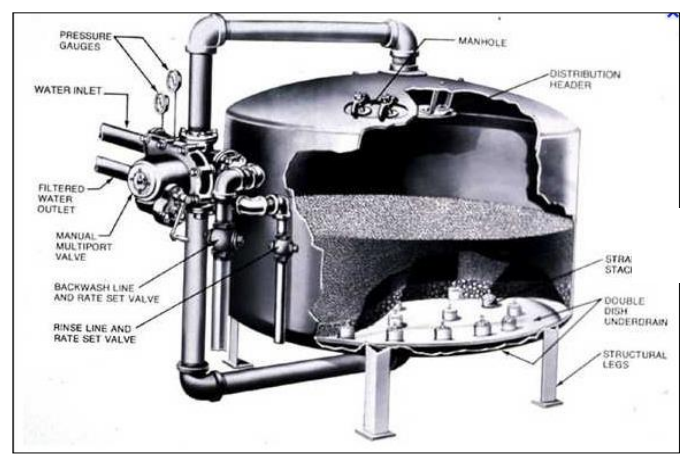

Fig: 6 Sectional view of pressure sand filter

Water to be disposed of often contains all solids that were originally produced and passed through various production equipment. To keep these solids from plugging disposal equipment, filters are often installed. Sand filters are steel vessels filled with sand. The sand is graded from coarse grains (where the water enters) to fine grains (where it leaves) to assure that all particles are removed. These sand filters are somewhat effective in removing oil as well as solids from water. The multiple surfaces of the sand grains offer places for the oil droplet to coalesce and stop in the filter. Oil and solids eventually plug the sand and must be removed. This is accomplished in an operation called backwashing in which the flow of water through the filter is reversed and forced to a tank where the solids can be collected and oil recovered.

\section{Dual Media Filter}

These dual media filters have high dirt removal efficiency of the size of fine sand particles. A thick layer of coarse anthracite is provided along with these filters. The sand and anthracite act as the filtering media and polishing media respectively. A inlet distributor and a bottom collecting system are internally fitted. Externally, it is fitted with frontal pipe work and isolation valves.

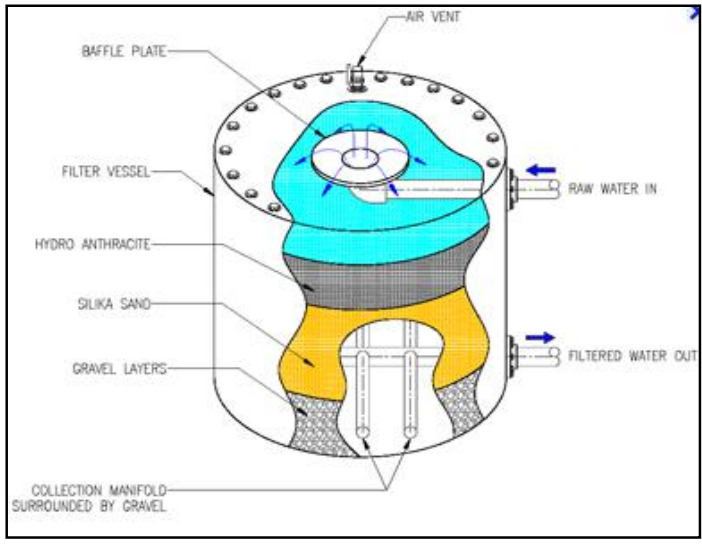


Fig: 7 Sectional view of Dual media filter

Sand is used for removing the suspended particles and anthracite removes the odor and color etc to make the water fit for various applications. Peebles and gravels are provided to support to both the media. This filter is to be backwashed after accumulation of suspended solids; however, before carrying out the backwash, air scouring is also to be done for loosening of dirt and suspended solids. Limit for the backwash in these filters is governed by differential pressure across the filter. This is the process that allows taking off the water all suspended solids which cause the turbidity of the water, like sludge, mud this process is used to filter water from wells water or from or from surface sources. The process simply consists of the following of the water through several layers of selected quartz sand with different grain sizes and layers of anthracite. The media filter is contained in vessel normally made in fiber glass or coated steel, or stainless steel. Usually the water flows from top to the bottom of the filter and the solids retained by the first layer of sand improves the action.

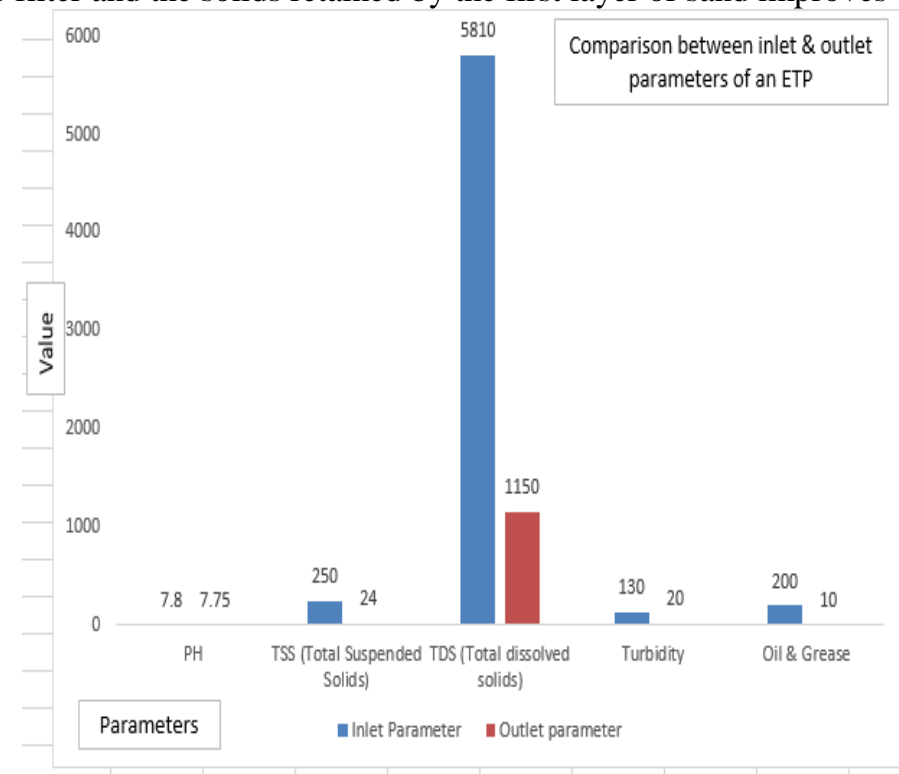

Fig: 8 Comparison of inlet and outlet parameters of an ETP

\section{Discussion}

The ETPs and WIPs of various fields of Assam are monitored by the measurements of the actual treated outlet values of $\mathrm{pH}$, TSS, Oil \& Grease and Turbidity to evaluate the percentage removal of the same.

1. $\mathrm{pH}$ : The $\mathrm{pH}$ values of all the ETPs and WIPs are within the specified range. In some fields the value of $\mathrm{pH}$ decreases because of decrease in alkalinity due to Alum (or PAC) dissociation leading to reduction in $\mathrm{pH}$ as compared to Inlet effluent. In some fields the value of $\mathrm{pH}$ is on a higher side compared to inlet effluent because of using Lime in conjunction with alum (or PAC) for coagulating suspended solids incident to the removal of turbidity from raw water. It serves to maintain the proper $\mathrm{pH}$ for the most satisfactory coagulation conditions. Since Lime solution gives rise to alkalinity which leads to increase in $\mathrm{pH}$ value as lime controls the environment required for the growth of bacteria and certain viruses.

2. Oil \& Grease: Oil \& Grease values of treated effluent for ETPs results in a good amount of removal against inlet effluent due to adding of a de-oiler solution which leads to good separation of free oil and emulsified oil. Oil \& Grease values of all the installation are well maintained within the range.

3. TSS and Turbidity: TSS and Turbidity values of treated effluent for ETPs are within or near the range of design parameter and results in a good amount of removal impurities due to adding of a polymer (or Polyelectrolyte) as coagulant and alum (or PAC) as a flocculating agent. Coagulation has the advantage of reducing the time required to settle out suspended solids. It is also very effective in removing fine particles which are otherwise very difficult to remove from water. Coagulation can also be effective in removing protozoa, bacteria and viruses, particularly when poly-electrolyte is used, as the highly charged coagulant attracts the charged microorganisms into the flocs. Coagulation can also be effective in removing by precipitation certain contaminants such as lead and barium.

\section{Conclusion}

Raw produced water is commonly regarded as a high-volume toxic waste but can be beneficial to humans if properly managed. The treatment of produced water is very important due to environmental concerns. In Assam, there is a great demand for the treatment of produced water as a source of fresh water, mainly due to the ever increasing population of Assam, which is above 3 crores. In produced water treatment, no single technology can meet suitable effluent characteristics; thus two or more treatment systems may have to be combined to make a hybrid system [10]. The choice of best technology is based on produced water chemistry, cost effectiveness, space availability, re-use and discharge plans, durable operation and byproducts. In Assam in all the fields most of the treated water quality parameters are being achieved for disposal purpose 
but to make this water usable for the purpose of agriculture, industry and other livestock activities it has to be further treated and the impurities has to be reduced to a minimum value. Moreover the technologies presently used in the oil fields of Assam are old leading to increase cost of operation and maintenance. Therefore time has come to review the latest technologies available in the market to arrive at some technologies which is cost effective, which gives better output in terms of percentage removal and which occupies minimum space, considering forthcoming challenges of rising water cut in old oilfields. Thermal produced water treatment technologies are mature but may not be relevant in future treatment unless significant reductions are made in energy costs. This may be achieved if low-pressure steam is available through cogeneration arrangements. Membrane technologies are some of the finest for produced water treatment today; however, significant progress must be made to reduce membrane fouling and secondary waste generation for them to compete well in the future management of produced water. High costs of rigorous pre-treatment, fouling, and regular backwashing are major setbacks of these technologies for future application [11, 12, 13]. Macro-porous polymer extraction (MPPE) technology is a fairly new produced water treatment technology that may well compete in the future management of produced water. Its potential to achieve a zero pollutant discharge and a significant reduction in energy consumption compared with thermal technologies are very promising, but advancement is needed to bring down its relatively high cost. [14, 15]. A cost-effective technology with zero pollutant discharge will be the technology of choice for the future management of produced water and this can be potentially achieved by electrochemistry. [16]. The application of electrochemically driven treatment technologies can lead to the production of clean water, production/storage of energy and recovery of valuable materials from produced water by integrating photo-electrochemistry, Electrodialysis, Electrodialysis reversal and other electrochemical techniques into a single electrochemical unit. This is an achievable engineering task that could make electrochemistry the future produced water treatment technology. Although electrochemistry is not yet a very popular method for the treatment of produced water today, it is very promising and may be the future technology for the management of produced water.

\section{References}

1. Reynolds Rodney R.: "Produced Water and Associated Issues," a manual for independent operator, Petroleum Technology Transfer Council (2003).

2. Veil J.A., Puder M.G., Elcock D., and Redweik R. Jr. J.: “A White Paper Describing Produced Water from Production of Crude Oil, Natural Gas, and Coal Bed Methane," US DOE (January 2004) W-31-109-Eng-38.

3. Amyx, J., D. Bass, and R.L. Whiting, 1960, Petroleum Reservoir Engineering, McGraw-

Hill Company, New York.

4. Tibbetts, P., Buchanan, I., Gawel, L., \& Large, R. (1992). A Comprehensive Determination of Produced Water Composition. In J. Ray, \& F. Engelhardt, Produced Water Technological/Environmental Issues and Solutions (p. Vol. 46 (1992) 97). New York: Plenum Press.

5. Draft Indian Standard DRINKING WATER - SPECIFICATION (Second Revision of IS10500).

6. H.K.Abdel-Aal, Mohamed Aggour, M. A. Fahim. Petroleum and Gas Field Processing.

7. Rubio, J., Souza, M., \& Smith, R. (2002). Overview of Flotation as a Wastewater Treatment Technique. Minerals Engineering 15, 139-155.

8. Strickland, W. (1980). Laborattory Results of Cleaning Produced Water by Gas Flotation. Society of Petroleum Engineering Journal 20, 175-190.

9. Gopalratnam, C., Bennett, G., \& Peters, R. (1988). The Simultaneous Removal of Oil and Heavy Metals from Industrial Wastewaters by Joint Precipitation and Air Flotation. Environmental Progress 7, 84-92.

10. Fakhru'l-Razi A, Pendashteh A, Abdullah LC, et al. Review of technologies for oil and gas produced water treatment. J Hazard Mater 2009; 170:530-51.

11. Y.S. Lia, L. Yana, C.B. Xiang, L.J. Hong, (2006). Treatment of oily wastewater by organic-inorganic composite tubular ultrafiltration (UF) membranes, Desalination 196 76-83.

12. T. Bilstad, E. Espedal, (1996). Membrane separation of produced water, Water Sci.Technol. 34 239-246.

13. L. Liangxiong, T.M. Whitworth, R. Lee, (2003) Separation of inorganic solutes from oil-field produced water using a compacted bentonite membrane, J. Membr. Sci. 217 215-225.

14. D.B. Burnett, Potential for Beneficial Use of Oil and Gas Produced Water, (2004) http://www.rrc.state.tx.us/commissioners/williams/environment/beneficial uses.

15. Toshikazu Ono, Takahiro Sugimoto, Seiji Shinkai and Kazuki Sada (2007) Lipophilic polyelectrolyte gels as superabsorbent polymers for nonpolar organic solvents, Nature materials Vol 6 429-433.

16. Elisama Vieira dos Santos \& Jessica Horacina Bezerra Rocha \& Danyelle Medeiros de Araújo \& Dayanne Chianca de Moura \& Carlos Alberto Martínez Huitle (2014), Decontamination of produced water containing petroleum hydrocarbons by electrochemical methods: a minireview, Environ Sci Pollut Res 21 8432-8441 